Western University

Scholarship@Western

FIMS Publications

Information \& Media Studies (FIMS) Faculty

2010

\title{
Persistence and change in social media
}

Bernie Hogan

University of Oxford

Anabel Quan-Haase

The University of Western Ontario, aquan@uwo.ca

Follow this and additional works at: https://ir.lib.uwo.ca/fimspub

Part of the Library and Information Science Commons

Citation of this paper:

Hogan, Bernie and Quan-Haase, Anabel, "Persistence and change in social media" (2010). FIMS Publications. 76.

https://ir.lib.uwo.ca/fimspub/76 


\section{Persistence and Change in Social Media}

Hogan, B., \& Quan-Haase, A. (2010). Persistence and change in social media: A framework of social practice. Bulletin of Science, Technology and Society, 30, 5, 309315. Retrieved from http://bst.sagepub.com/content/30/5/309.full.pdf $+\mathrm{html}$.

\section{Bernie Hogan ${ }^{1}$ and Anabel Quan-Haase ${ }^{2}$}

${ }^{1}$ University of Oxford, Oxford, United Kingdom

${ }^{2}$ University of Western Ontario, London, Ontario, Canada

\section{Corresponding Author:}

Bernie Hogan, University of Oxford, Oxford, United Kingdom

1 St Giles, Oxford, UK, OX1 3JS

Email: bernie.hogan@oii.ox.ac.uk

\section{Introduction}

In "Star Trek", Scotty suggests that Transwarp beaming is "like trying to hit a bullet with a smaller bullet, whilst wearing a blindfold, riding a horse" (Abrams, 2009). The study of social media faces similar challenges because new tools are developed at a rapid pace and existing tools are constantly being updated with new features, policies, and applications. Users tend to migrate, in often unpredictable ways, to new tools as well as to adopt multiple tools simultaneously, without showing consistent media preferences and habits (Quan-Haase, 2008). As a result, for scholars it sometimes feels as if the social media landscape changes too quickly to fully grasp and leaves scholars permanently lagging behind. We argue in this paper that beyond the ebb and flow of everyday events and seemingly idiosyncratic usage, trends exist underlying long-term trajectories, persistent social practices, and discernable cultural patterns.

Overarching findings have emerged within and across disciplines because the study of social media has from its early beginnings necessitated a multi-disciplinary approach. From power laws to impression management, from privacy concerns to online social capital, there is a great onrush of scholarship on social media, its properties, and its consequences. Regardless of discipline, all scholars face the challenge of constant change occurring in this arena. This challenge exists on a number of different levels. On a practical level, research and publication timelines continue to be slow relative to the rapid transformation occurring in social media. This rapid change is particularly prominent with the study of social network sites, where both the popularity of certain sites and their privacy policies continue to be in continual flux (boyd, 2006; boyd, 2007; Gross \& Acquisti, 2005; Tufekci, 2008; Young \& Quan-Haase, 2009). On an applied level, challenges exist in teaching social media theory and methods because best practices and understandings quickly become obsolete. On a theoretical level, generalizable claims need to be constantly updated to reflect the new realities in policy, features, and usage.

This issue of the Bulletin of Science, Technology and Society on "Persistence and Change in Social Media" compiles a series of papers to identify elements of social media practice that are persistent across platforms, users, and cultures. The goal of this special issue is not only to present articles addressing current topics and the 
current state of knowledge, but also to present research pointing toward the long-term trajectory of social media development and usage. In this paper, we propose the term social media practice as a means to overcome the transient nature of the phenomena encountered on social media, and identify practices that are stable and universal. We argue that through a focus on the practices involved in the domestication and mainstreaming of social media, it is possible to develop more robust theories and present widely applicable findings.

Because social media are a moving target, it is impossible to provide concrete answers to many research questions and to resolve conclusively existing debates about the long-term trajectory of social media. For example, there will never be a single and ideal way to self-present on social network sites (Tufekci, 2008), or a perfect hyperlink to place on one's website. Despite the intangibility of the subject, recurring insights emerge. We list four examples of findings that have shown some stability:

- Strong, intimate social relationships online tend to be also strong, intimate social relationships offline (Ellison, Steinfield, \& Lampe, 2007) (Dutton, Helsper, and Gerber, 2009; Hampton, 2009).

- People who tend to communicate more online also tend to do so offline (Quan-Haase, 2008; Wellman, Quan-Haase, Witte, \& Hampton, 2001).

- The distribution of contacts will always be skewed with few friends being close and the majority being weak (Roberts et al., 2009; Lewis et al., 2008).

- There will be a gap between what users say they do and what they actually do as the investigation of privacy concerns on social network sites has shown (Gross \& Acquisti, 2005; Young \& Quan-Haase, 2009).

The goal of this paper on persistence and change in social media is to take the findings from the articles compiled in this special issue and extend these claims with an eye towards the aspects of social media that may persist for years, if not decades. We hope that our discussion of social media practice will provide an overarching framework from which future research can draw.

\section{A Definition of Social Media}

Identifying the unique qualities of social media is challenging since all media have a social element. Moreover, most social media integrate other forms of computermediated communication (CMC). For example, Facebook, MySpace, and Twitter all have direct messaging systems akin to email, whereas dating sites embed instant messaging (IM), friend testimonials, and blogging features alongside their core feature of profile searching. In other words, no standards exist and there is no single "killer app" entailed in all social media sites. Different sites have different historical trajectories as they co-evolve with their user base. For example, Hi5, LinkedIn, and MySpace have all introduced a means to see who has viewed one's profile, while Facebook has explicitly banned any such activity.

For this reason, we emphasize the social affordances of social media. Affordances refer to perceptual cues in the environment that facilitate interaction (Gibson, 1986). The classic example is a chair-its height and shape can be perceived as affording sitting, so someone can sit on it. Norman (1990) describes how doors that have horizontal handles afford pushing, while vertical ones afford pulling. A special class of affordances, termed social affordances, have long been discussed in studies of CMC (Gaver, 1996; Bradner et al., 1999; Wellman et al., 2003). These affordances 
allow individuals to perceive aspects of their social environment, such as who else is in a chat room, who was co-sent a message, or who are the friends of my friends on a social network site.

In this framework, social media afford two-way interaction with an audience, beyond any specific recipient. This form of communication falls under the term "many-to-many" (Shirky, 2009; Rafaeli and LaRose, 1993), which has been used to describe the nature of interaction on listservs, blogs, and Internet Relay Chat (IRC). In many-to-many communication, messages are broadcast to a wider audience that can then engage in an exchange. Next we compare the social affordance of a two-way audience to that of one-way media and classic two-way media.

\section{One-way media, two-way media, and the two-way audience}

Media that tend to convey information in a one-directional manner are described as one-way, that is, from source to audience. Examples of one-directional media include broadcast radio and television. For audiences to provide feedback in one-way media is cumbersome and requires the use of another communication medium. A good example of this is vote-in shows, such as Eurovision and American Idol. For audience members to participate in vote-in shows, they have to call on a telephone or from a cell phone, rather than being able to press simply a button on their screen to provide their input. Radio similarly requires people to email, text (SMS), or call to make a request or provide input. More importantly, in this form of media a clear distinction exists between the producer of content and the audience; in these settings audiences are rather passive recipients of information. ${ }^{1}$

A second class of media are described as two-way because they support direct communication between two individuals or a small group of individuals and hence are interactive. Examples of two-way media are email and the telephone. For these media information is sent by a sender and received by specifically addressed recipient(s). One person calls another or sends email to specific other individuals.

Social media combines features of one-way media and two-way media. Like one-way media, information is broadcast from one source to a (potentially unknown) audience. But like two-way media, individuals can react and respond to this communication through the same channels.

Our discussion of the term social media indicates that the boundaries of this term are not straightforward (Woolgar, 1991). Certain media will be on the fringes of social media, with their inclusion endlessly debated. Social network software is clearly inside that boundary, and the television is clearly outside. But what about IM? Does IM have an audience or just direct recipients? How is IM different from onedirectional media, such as television, or two-directional media, such as the telephone? IM clearly is not part of one-directional media because users can easily provide input and exchange messages without needing to switch media. IM has some notion of a two-way audience not in the direct conversations, but rather in the buddy list that broadcasts users' current availability and customizable status messages. These two features make IM a many-to-many communication tool as this information is

${ }^{1}$ Here, following Ha and James (1998), we mean passive in the sense that individuals do not get to communicate directly with the senders of communication. We acknowledge the copious scholarship on how audiences actively make sense of media (Fiske, 1989; Ang, 1986) even if they do not get to communicate with producers directly. 
available to the entire social network and it is not directed at a specific person. In fact, these status messages and availability signals are very clearly designed to speak to the entire buddy list (i.e., the potential audience) about the individual's mood and his current accessibility (Nardi, Whittaker, \& Bradner, 2000; Quan-Haase \& Collins, 2008). Hence, certain features of IM make them social media in the same way that certain features of social network sites make them one-to-one media (e.g., the private conversations and chats).

Is a two-way audience a necessary condition for social media? That is, can we have social media without such an audience? This issue may never be resolved.

However, we are confident that if a medium includes a two-way audience it would be safe to call it social media, thereby suggesting "many-to-many" communication is a sufficient but not necessary condition for social media. More to the point, we are not interested in simply debating what social media are when there are so many unresolved questions about what social media mean in the everyday lives of users (Quan-Haase \& Young, this issue). What does it mean when someone dies and their profile lives on (Carroll \& Landry, this issue), or when a controversial issue such as abortion is debated in full public display (Yardi \& boyd, this issue)? What does it mean when people can blog about fraudulent elections or organize protests virtually (Ifukor, this issue)?

These topics are aptly discussed in this issue. Herein we learn how two-way audiences reframe content from mainstream media, such as when people post a link to a breaking news story, but add their own headline (Yardi \& boyd, this issue). These audiences also reframe each other's online identity, such as when individuals post public testimonials on MySpace profiles of deceased friends (Carroll \& Landry, this issue). People now project their two-way conversation onto others whom they would otherwise consider inaccessible, like major politicians and celebrities (Sanderson \& Cheong, this issue). And finally, because participation is both in the open and digital, all of this participation can be resorted, filtered, remixed, and mashed up. Thus, people can participate not only through the creation of content, but the reorganization of content, through new curation practices or even just by drawing attention to the content of others (Erickson, this issue; Hogan, this issue).

\section{After-Death: the Persistence of Digital Traces}

The web started over 20 years ago as a collection of webpages accessible via hyperlinks (Leiner et al., 1997). While many webpages have been taken offline, their remnants persist in the Internet Archive's Wayback machine. Webpages, such as those found on the now defunct Geocities, resembled texts or documents, only hyperlinked. Indeed, they were analyzed as such (Thelwall, 2004; Park, 2003; Herring \& Martinson, 2002). While websites had authors, the focus was usually on content. If authors of websites died, the webpage might be considered as something they have 'left behind' in the digital realm. Because author and content were only loosely linked via authorship, the death of the author did not directly impact the content and how it was used online.

Death plays out very differently in the context of social media because author and content are closely intertwined. Participation via social media involves a host of small cumulative activities such as editing a profile, uploading pictures, and adding status and availability information. All of these social practices together create a very personal portrait of an individual and her online persona - one that is closely linked with her identity (boyd, 2006; Reed, 2005; Sundén, 2003). But as Hogan (this issue) notes, all of this submitted content still exists outside of the self in a sort of virtual 
exhibition. Because of the interactivity of the sites, it is easy to consider this exhibition as a living performance. When the submitter of this content is still living, we can maintain the illusion that submitter and submitted content are one. But when the submitter dies and the profile lives on, we can see this distinction all too clearly. Death has become the ultimate arbiter of this difference between the data that persists and the individual that does not.

In our initial call for papers, death was not among the topics presented. Yet, three of the papers included in this issue address the topic of death and grieving online. For Yardi and boyd (this issue), it is about the polarized public framing of the assassination of an abortion doctor on Twitter. For Sanderson and Cheong (this issue), it is the public grieving of Michael Jackson on Facebook and MySpace-easily the most spectacular individual death of this past year, if not this past decade. And Carroll and Landry (this issue) deal with the persistent online presence of personally known individuals, and how their MySpace and Facebook pages are transformed either literally or metaphorically into memorial pages and sites of grieving.

The focus on death reflects a change that the Internet has undergone during the past two decades: its domestication and mainstreaming (Wacjman, 2008; (Herring, 2004; Wellman \& Haythornthwaite, 2002). Early Net culture was the play of academics, hackers, and geeks, who embraced the web as a means, among other things, to exchange information and to collaborate (Castells, 2001; Turner, 2006). Since Internet use is almost ubiquitous in Western countries and social media have been widely adopted by the general population (Hampton et al., 2009; Dutton et al., 2009), one (perhaps unexpected) consequence has been the need to confront death within social media. We have observed two interesting developments in this regard. First, high profile cases have drawn the interest and engagement from the larger online community, such as the death of Michael Jackson (Sanderson and Cheong, this issue), the death of abortion doctor Dr. Tiller (Yardi \& body, this issue) and the struggles of baby Isaiah's family. These cases have shown that people come together online after death to commemorate, to grieve, to debate, to sympathize, and to provide emotional, social, and economic support. Second, after death profiles are recreated and reframed as a means to remember and to memorialize those who have passed away (Caroll \& Landry, this issue). The grieving of a participatory audience is quite different from the presentation of death in traditional one-way media. Television and newspapers provided information about the suffering and death of celebrities and public figures alongside public obituaries for anyone who was recently deceased. Audiences, however, were scarcely able to share their emotions, opinions, and reactions with a larger community. Social media changes the dynamics providing audiences with new ways to express their mourning, to negotiate the meaning of the death of a celebrity, public figure, or loved one, and to deal with loss as a community.

\section{Curation}

The traditional notion of a curator is a trained expert who selects the finest objects and arranges them in a careful and meaningful way. This is curation in a world of scarce and precious objects. By contrast, social media is not a world of precious scarcity, but of data abundance. Digital media can be copied, transferred, filtered, remixed, and sorted on the fly. As noted by both Hogan and Erickson (this issue), curating such digital material is qualitatively different. Hogan (this issue) seeks to distil curation to some basic elements: filtering, ordering, and searching that can be done by algorithms. For him, what is key is that personalized exhibitions can be created with asynchronous social media. By contrast, Erikson (this issue) portrays the curation of 
digital artefacts as a very personal activity. In her study, digital curators select places with personal, cultural or national relevance and portray them in unique ways through their photography. She discusses how different photographers are using documentary practices to curate their digital objects, and how this curation is affected by advances in geo-location data creating digital traces of physical places that resemble galleries or museums.

The curation of digital artefacts will likely end up in a constant state of tension. How much of this can be done by an algorithm, whether it is a corporate database, such as Facebook or Google, or a personalized agent/companion (c.f. Wilks 2010)? How much will be done by people? Erikson's study shows how place and person-based curation, or "socio-locative broadcasting" has evolved as a new practice within social media. Such curated sets can now be found in Flickr and Jaiku among other places. Through the merger of a representation of a physical place via photos with its geo-location, the place becomes both a location in space as well as a cultural, personal artefact that can be shared with an audience.

\section{Framing}

From retweets to "demotivational posters" (a genre of online photos that mock motivational posters with pictures and humorous captions), from YouTube video replies to comments on Facebook comments, it seems that social media involve a near infinite recursion of framing practices (Goffman, 1974). Seldom do people pass information or a link without editorializing it somehow or adding their personal opinion. In Carroll and Landry's (this issue) work on death, they mention how memorials of others are partially an attempt to reframe the dead in relation to the writer of the memorial and his relationship to the deceased person. Similarly, Yardi and boyd's (this issue) paper focuses on the polarized framing of Dr. Tiller's death. In Dr. Tiller's case, the framing was considered a political act rather than a personal one and it thereby led to emergent social groupings based on politics. The documentarian practices of digital curators in Erikson's (this issue) work are similarly an attempt to reframe a picture and to take it out of its 'original' context of a photoset, and place it in another context meaningful to the curator. Ifukor (this issue) elaborates on this framing practice in relation to the protracted 2007 Nigerian elections. Framing there consists of describing how the elections themselves unfolded, how people reacted to the election, and what the problems confronted during the election mean for those involved.

Framing (and reframing) highlights how social media are not simply about the creation of new content, or the revealing of personal details. Blogs are not simply about introducing new information, but reorganizing information into personally meaningful ways. Twitter is not simply about what people had for lunch. Social media allow people to reinterpret culture on the fly. While the specific genre or mechanism of framing will undoubtedly shift over time, it appears that the practice of framing is a persistent feature of social media.

\section{Social Media Adoption and Practice}

If IM is on the fringes of social media and social network sites are exemplars, this makes IM and Facebook useful test cases for how people interpret social media. Quan-Haase and Young (this issue) compare these two media in this issue, noting that Facebook is perceived as a leisure pastime where one can connect with friends, while IM is more useful for social and emotional. IM tends to support best dyadic 
exchanges characterized by intimacy and a deep level of engagement, whereas Facebook provides a platform for broadcasting ideas, thoughts, and feelings to a wider audience composed of close and distant friends as well as friends of friends. IM primarily promotes real-time communication where interactivity and engagement are central, whereas Facebook promotes asynchronous interaction with flexible engagement. Facebook affords users to create large networks composed of weak and strong ties, whereas IM is used more to maintain intimate relationships that require indepth exchanges. Each form of social media has developed its own niche in terms of the kinds of communicative practices that it supports.

Further in the issue, Latzko-Toth distinguishes between two different forms of synchronous communication: conference, which refers to a gathering in a virtual place were unfocussed interactions and group sociability occur, and copresence, where practices are centered around the sustainment of contact between individuals who know each other. Social media today blend both forms of communication providing a forum for unfocused synchronous exchanges and network sociability as well as a space where people who know each other can stay loosely connected (Van Cleemput, 2010). Historical analyses, like the one provided by Latzko-Toth (this issue) of synchronous communication, are rich and help understand how the development and adoption of social media has occurred.

\section{A long term view on social media}

We end where we started: How can we analyze social media in such ways that our work is neither fleeting nor irrelevant when the next platform comes along? The answers are not obvious, but the articles in this issue help us towards that end. Based on our discussion of the articles published in this issue and work in the field, we identify the following enduring social practices of social media:

- Different forms of CMC afford many different social practices (e.g., chat, social tagging, asynchronous messaging, gift-giving or profile viewing statistics). Despite their variety, one common thread in these practices is whether they facilitate one-way, two-way or many-to-many interaction. Social media tends to facilitate many-to-many interaction.

- In the days before social media, scholars and the lay public focused on the distinction between the online and offline world, as if they were separate entities (Haythornthwaite \& Wellman, 2002; Turkle, 1997). Social media tends to refer to and reflect the offline world. The real distinction is not 'the online self' from the 'offline self', but the mind-in-the-present that interacts with others compared to the digital traces left behind that can be redistributed to audiences. This distinction is particularly evident when an individual dies and his data lives on.

- In theory, data submitted to social media can be persistent. In reality, most social media practice is oriented towards the shared present. Users constantly update data and the traces of the data vanish in the archives. Social media focus on the unfolding in the here and now of cultural, environmental and political events and people's lives.

- Curating data can take many forms: from the simplest ability to filter and order to the most complex collaborative recommender algorithm or a carefully annotated slideshow. How users curate data is meaningful and carries a signal to their audience. In some cases algorithms suffice, but in other cases users seek to curate data themselves to (re)frame a message, idea, picture, or person. 
- Research on social media does not necessarily warrant new theories of communication. Existing theories, such as uses and gratifications, impression management and homophily can be honed, scoped and elaborated, as researchers compare platforms, users, and practices across the rapidly expanding social media ecology.

This issue on "Persistence and Change in Social Media" of the Bulletin of Science, Technology and Society only scratches the surface, and yet still covers a great deal of ground. The issue brings together a wide range of theories, data collection methods, approaches to data analysis, and interpretative viewpoints. Undoubtedly, work in the future will not only be more specific and extensive, but also have the benefit of hindsight, as we do of early Internet scholarship. Discerning the constant from the variable phenomena in the social media landscape will allow us to push this work even further towards greater understanding of users, adoption trends, social practice, norms, and cultural patterns.

\section{References}

Abrams, J.J. (Producer, Director). (2009). Star Trek [Motion Picture]. United States. Paramount Pictures.

Ang, I. (1989). Watching Dallas: Soap Opera and the Melodramatic Imagination. New York: Routledge.

boyd, d. (2006). Friends, Friendsters, and Top 8: Writing community into being on social network sites [Electronic Version]. First Monday, 11. Retrieved December 15, 2008 from http://firstmonday.org/htbin/cgiwrap/bin/ojs/index.php/fm/article/view/1418/1 336.

boyd, d. (2007). Why youth (heart) social network sites: The role of networked publics in teenage social life. In D. Buckingham (Ed.), The MacArthur Foundation Series on Digital Learning - Youth, Identity and Digital Media Volume. Cambridge, MA: MIT Press.

Bradner, E., Kellogg, W. A., and Erickson, T. (1999). The adoption and use of 'Babble': A field study of chat in the workplace. Proceedings of the Sixth European conference on Computer Supported Cooperative Work, pages 139158.

Castells, M. (2001). The Internet Galaxy: Reflections on the Internet, Business, and Society. Oxford: Oxford University Press.

Dutton, W., Helsper, E. J., and Gerber, M. M. (2009). The Internet in Britain: 2009. Oxford Internet Institute, University of Oxford.

Ellison, N. B., Steinfield, C., \& Lampe, C. (2007). The benefits of facebook "Friends:" Social capital and college students' use of online social network sites [Electronic Version]. Journal of Computer-Mediated Communication, 12, 4 article 1. Retrieved December 15, 2008 from http://jcmc.indiana.edu/vol12/issue4/ellison.html.

Fiske, J. (1987). Television Culture. New York: Routledge.

Gibson, J. J. (1986). The Ecological Approach to Visual Perception. Hillsdale, NJ: Lawrence Erlbaum Associates.

Goffman, E. (1974). Frame Analysis: An Essay on the Organization of Experience. London: Harper \& Row. 
Ha, L., \& James, E. L. (1998). Interactivity re-examined: A baseline analysis of early business websites. Journal of Broadcasting \& Electronic Media, 42(4), 457474.

Gross, R., \& Acquisti, A. (2005). Information revelation and privacy in online social networks. In Proceedings of the 2005 ACM workshop on Privacy in the electronic society, November 7, 2005. Alexandria, VA: ACM Press.

Hampton, K., Sessions, L., Her, E. J., and Rainie, L. (2009). Social Isolation and New Technology. Pew Internet and American Life Project, Washington, D.C.

Haythornthwaite, C. and Wellman, B. (2002). The Internet in Everyday Life: An Introduction. In B. Wellman \& C. Haythornthwaite, The Internet in Everyday Life (pp. 3-41). Malden, MA: Blackwell Publishers.

Herring, S. C. (2004). Slouching toward the ordinary: Current trends in computermediated communication. New Media and Society, 6(1), 26-36.

Herring, S. C. and Martinson, A. (2002). Designing for community - the effects of gender representation in videos on a web site. In Proceedings of the $35^{\text {th }}$ Hawaii International Conference on System Sciences, Hawaii.

Leiner, B. M., Cerf, V. G., David D, C., Kahn, R. E., Kleinrock, L., Lynch, D. C., et al. (1997). The past and future history of the internet. Communications of the ACM, 40(2), 102-108.

Lewis, K., Kaufman, J., Gonzalez, M., Wimmer, A., and Christakis, N. (2008). Tastes, ties, and time: A new social network dataset using facebook.com. Social Networks, 30(4):330-342.

Nardi, B. A., Whittaker, S., \& Bradner, E. (2000). Interaction and outeraction: Instant messaging in action, Conference on Computer Supported Cooperative Work (CSCW) (pp. 79-88). Philadelphia, Pennsylvania, December 2-6: ACM, Inc.

Norman, D. A. (1990). The Design of Everyday Things. New York: Basic Books.

Park, H. W. (2003). Hyperlink network analysis: A new method for the study of social structure on the web. Connections, 25(1), 49-61.

Quan-Haase, A. (2008). University students' local and distant social ties: Using and integrating modes of communication on campus. Information, Communication \& Society, 10(5), 671-693.

Quan-Haase, A., \& Collins, J. L. (2008). "I'm there, but I might not want to talk to you": University students' social accessibility in instant messaging. Information, Communication \& Society, 11(4), 526-543.

Rafaeli, S. and LaRose, R. (1993). Electronic bulletin boards and "public goods" explanations of collaborative mass media. Communication Research, 20, 277277.

Reed, A. (2005). 'my blog is me': Texts and persons in UK online journal culture (and anthropology). Ethnos, 70(2), 220-242.

Roberts, S., Dunbar, R., Pollet, T., and Kuppens, T. (2009). Exploring variation in active network size: Constraints and ego characteristics. Social Networks, $31(2), 138-146$.

Shirky, C. (2008). Here Comes Everybody: The Power of Organizing without Organizations. Penguin Books Ltd.

Sundén, J. (2003). Material Virtualities: Approaching Online Textual Embodiment. New York: Peter Lang Publishing.

Thelwall, M. (2004). Link Analysis: An Information Science Approach. Elsevier, Amsterdam. 
Tufekci, Z. (2008). Can you see me now? Audience and disclosure regulation in online social network sites. Bulletin of Science, Technology and Society, 28(20), 20-36.

Turkle, S. (1997). Life on the Screen: Identity in the Age of the Internet. New York: Simon \& Schuster.

Turner, F. (2006). From Counterculture to Cyberculture. Chicago, IL: Chicago University Press.

Van Cleemput, K. (2010) "I'll see you on IM, text or call you": A social network approach of adolescents' use of communication media. Bulletin of Science, Technology and Society, 30, 75-85. DOI: 10.1177/0270467610363143.

Wajcman, J. (2008). Life in the fast lane? Towards a sociology of technology and time. British Journal of Sociology, 59(1), 59-77.

Wellman, B., \& Haythornthwaite, C. (Eds.). (2002). The Internet in Everyday Life. Oxford: Blackwell Publishers.

Wellman, B., Quan-Haase, A., Boase, J., Chen, W., Hampton, K., Isla de Diaz, I., and Miyata, K. (2003). The social affordances of the Internet for net-worked individualism. Journal of Computer Mediated Communication, 8(3). Retrieved from http://jcmc.indiana.edu/vol8/issue3/wellman.html.

Wellman, B., Quan-Haase, A., Witte, J., \& Hampton, K. (2001). Does the internet increase, decrease, or supplement social capital? Social networks, participation, and community commitment. American Behavioral Scientist, 45(3), 437-456.

Wilks, Y. (Ed). (2010). Close Engagements with Artificial Companions: Key Social, Psychological, Ethical and Design Issues. Amsterdam, NL: John Benjamins Publishing.

Woolgar, S. (1991). A sociology of monsters: essays on power, technology and domination, chapter Configuring the user: the case of usability trials, pages 58-97. Routledge, London.

Young, A. L., \& Quan-Haase, A. (2009, June). Information revelation and internet privacy concerns on social network sites: A case study of Facebook. Proceedings of the Fourth International Conference on Communities and Technologies, University Park, PA, USA, June 25-27, 2009 (pp. 265-274). Dordrecht: Springer Verlag.

\section{Bio}

Anabel Quan-Haase is Assistant Professor of Information and Media Studies and Sociology at the University of Western Ontario. Her research investigates the interplay of the social and technological with a specific focus on social networks, social capital, and community.

Bernie Hogan is a Research Fellow at the Oxford Internet Institute at the University of Oxford. His research focuses on the interplay between public and private boundaries online as well as the joint use of multiple media. 